\title{
An Environmental Flow Framework for Riverine Macroinvertebrates During Dry and Wet Seasons Through Non-linear Ecological Modeling
}

\author{
Qingyi Luo ${ }^{1,2}$, Ming-Chih Chiu ${ }^{1,3}$, Lu Tan $^{1}$ and Qinghua Cai ${ }^{1 *}$ \\ ${ }^{1}$ State Key Laboratory of Freshwater Ecology and Biotechnology, Institute of Hydrobiology, Chinese Academy of Sciences, \\ Wuhan, China, ${ }^{2}$ College of Advanced Agricultural Sciences, University of Chinese Academy of Sciences, Beijing, China, \\ ${ }^{3}$ Department of Civil and Environmental Engineering, Ehime University, Matsuyama, Japan
}

OPEN ACCESS

Edited by:

Alexei B. Ryabov,

University of Oldenburg, Germany

Reviewed by:

Alban Kuriqi,

Universidade de Lisboa, Portugal

Marcos Callisto,

Federal University of Minas

Gerais, Brazil

*Correspondence:

Qinghua Cai

qhcai@ihb.ac.cn

Specialty section:

This article was submitted to

Population, Community, and

Ecosystem Dynamics,

a section of the journal

Frontiers in Ecology and Evolution

Received: 01 July 2021

Accepted: 19 August 2021

Published: 17 September 2021

Citation:

Luo Q, Chiu M-C, Tan L and Cai Q

(2021) An Environmental Flow

Framework for Riverine Macroinvertebrates During Dry and Wet Seasons Through Non-linear Ecological Modeling.

Front. Ecol. Evol. 9:734716

doi: 10.3389/fevo.2021.734716
A suitable environmental flow is critical for the functional maintenance of riverine ecosystems. Hydropower plants alter the flow regime by decreasing or even drying up the streamflow downstream of the dams, thereby affecting ecosystem sustainability. In this study, we aimed to develop a robust environmental flow framework that can provide scientific evidence for sustainable water resource management. Using ecological niche modeling based on non-linear responses of species to habitat factors, we assessed the environmental flow in the Xiangxi River Basin of Central China during dry and wet seasons from a multi-year perspective. The most abundant macroinvertebrate taxon (i.e., Baetis) was selected for model testing. The results showed seasonal differences in the minimum ecological water requirements and optimal environmental flow. These two hydrological metrics were higher during the wet season than during the dry season. During the dry season, the minimum ecological water requirement of Baetis was $1.3 \mathrm{~m}^{3} \cdot \mathrm{s}^{-1}$, and the optimal environmental flow was $1.6 \mathrm{~m}^{3} \cdot \mathrm{s}^{-1}$. During the wet season, the minimum ecological water requirement of Baetis was $2.5 \mathrm{~m}^{3} \cdot \mathrm{s}^{-1}$, and the optimal environmental flow was $2.6 \mathrm{~m}^{3} \cdot \mathrm{s}^{-1}$. This study provides a theoretical basis for the robust management of water resources in river basins.

Keywords: Xiangxi River Basin, instream flow incremental methodology, water requirement, optimal environmental flow, non-linear ecological modeling

\section{INTRODUCTION}

River ecosystems have an enormous capacity to provide food and shelter for aquatic species and offer a wide range of ecosystem services that directly affect human well-being (Kuriqi et al., 2021). However, trade-offs exist between economic development and environmental protection. With the vigorous development of the economy and modern industry, energy shortage has become a great threat to restrict sustained economic growth. To develop water resources and narrow the economic 
gap among regions, the construction of hydropower plants and other water conservancy projects in mountain streams has undoubtedly solved the huge problem of economic development (Pang et al., 2015; Wang, 2019). Nevertheless, with the development of clean energy, there are potential environmental hazards (Premalatha et al., 2014). For example, the construction of hydropower plants has destroyed the natural conditions of streams. In addition, the original ecological balance and seasonality of streams have been disrupted by the decrease in flow, cutoff of water flow, and dry up of rivers (Wellnitz, 2014; Ali et al., 2019; Branco et al., 2019; Ruocco et al., 2019). The construction of small hydropower plants has a small impact on the chemical factors, but it has a large impact on physical factors such as the flow velocity and water depth of the stream (Wang et al., 2013). In China, the construction of small hydropower plants reduced the similarity of macroinvertebrate communities in different river sections; the reservoir area is the region where the impact is the largest (Zhao et al., 2015). There is evidence that small hydropower plants, such as run-of-river hydroelectric plants, damage macroinvertebrate communities (Prota Salomão et al., 2019), affect vertical connections, and reduce lotic habitats (Pragana et al., 2017). Furthermore, it may lead to water peaking (Kuriqi et al., 2020) even at a low intensity, affecting riparian plaques (Aguiar et al., 2016), and may alter other sediment transport processes (Kuriqi et al., 2020). Therefore, suitable environmental flow can provide a technical route for mitigating the damage caused by hydropower plants in river and stream ecosystems (Alsterberg et al., 2017; Hong et al., 2018).

Therefore, natural flow regimes play a fundamental role as the primary driver in several biological processes and ensure the long-term ecological viability of aquatic habitats (Poff, 2018). Inadequate management of water resource exploitation may seriously damage the integrity of river ecosystems (Bunn and Arthington, 2002; Mittal et al., 2015). A water-energy-ecosystem nexus represents a complex interrelationship that depends on the type of habitat and flow regime. For example, an unsuitable environmental flow may adversely affect river ecosystems and hydropower revenue (Kuriqi et al., 2020). The environmental factors that influence the habitats of aquatic organisms mainly include river width, velocity, water depth, and physical habitat structure. River width determines the living area of aquatic organisms, and velocity is an important factor for aquatic organisms to choose their habitats. In the same river course, there are different submerged areas under different flows, and the effective areas for aquatic organisms to grow, reproduce, and forage are different. These factors are important determinants of the abundance and distribution of aquatic organisms (Stalnaker et al., 1995). Considering the importance of the effective habitat area of river channels to riverine species (e.g., fish), the habitat simulation method was used to establish the relationship between the habitat area and flow discharge for riverine organisms ( $\mathrm{Li}$ and Xia, 2011).

Currently, the methods for assessing ecological water requirements can be divided into the following four categories: hydraulic, hydrological, habitat, and holistic methods (Tharme, 2003; Ahmadi-Nedushan et al., 2006; Halleraker et al., 2007). Among them, the habitat method is relatively reliable for river channels (Alsterberg et al., 2017; Yi and Zhang, 2019; Zhang, 2019). The method is based on the relationship between the preferred habitat conditions required by organisms and hydrological environmental conditions. The relationship between indicator species and suitable habitat is highly realistic because it relies on a large number of field sampling and monitoring data (Tharme, 2003; Alsterberg et al., 2017; Yi and Zhang, 2019). Assessments and models of environmental flow have gradually received attention when applied to limited species (usually having commercial value or are endangered aquatic organisms), a single biological community (e.g., riverine invertebrates), and few ecosystem processes (e.g., primary or secondary productivity) (Arthington et al., 2018).

To our knowledge, there is no research framework that considers non-linear habitat suitability for macroinvertebrate species based on the ecological water requirement of rivers subject to small hydropower plants during dry and wet seasons, especially in the monsoon or Mediterranean areas (e.g., Asia) because monsoon and Mediterranean climates lead to seasonal fluctuations under hydrological conditions. In a previous study, the time series was simulated by using the simulated flow data of the hydrological model of the selected basin (i.e., the Drin River Basin located in the southwestern Balkans) to evaluate the environmental flow under the influence of dams (Papadaki and Dimitriou, 2021). Furthermore, an assessment of environmental flow was carried out at a small impounding site in northwestern England using velocity measurements and sample data from typical species of macroinvertebrates (Hough et al., 2019). Notably, habitat suitability models developed in different stream and river systems have limited applications in target systems. For example, one habitat suitability model developed in the United States was applied to a diversion power station in the mainstream of China (Fu et al., 2008); this model provided unrealistic and unpredictable results. Therefore, a specific habitat suitability model should be established for this river basin. A previous study estimated the minimum ecological water requirement based on the data from the impacted river reach downstream of the hydropower station (Li et al., 2008). Seasonal changes should be considered when the required ecological discharge varies during different periods of the year ( $\mathrm{Li}$ et al., 2012a,b; Huang et al., 2019). However, many studies have not considered the seasonal changes. In addition, natural rivers without human interferences should be selected to accurately estimate the environmental flow required to maintain the natural flow regimes.

This study assessed the seasonal environmental flow requirements of macroinvertebrates using non-linear ecological modeling based on multi-year data. Owing to climatic influences, rainfall and stream hydrology in monsoon Asia or Mediterranean regions have significant seasonal fluctuations. Maintaining the maximum biodiversity of streams throughout the year and the balance of ecosystems requires more accurate estimations of ecological flow. Considering the Xiangxi River Basin of Central China as a case study, the temporal rainfall is divided into two periods, namely, the dry season (January-March and October-December) and the wet season (April-September). Based on the multi-year monitoring data, we selected the 


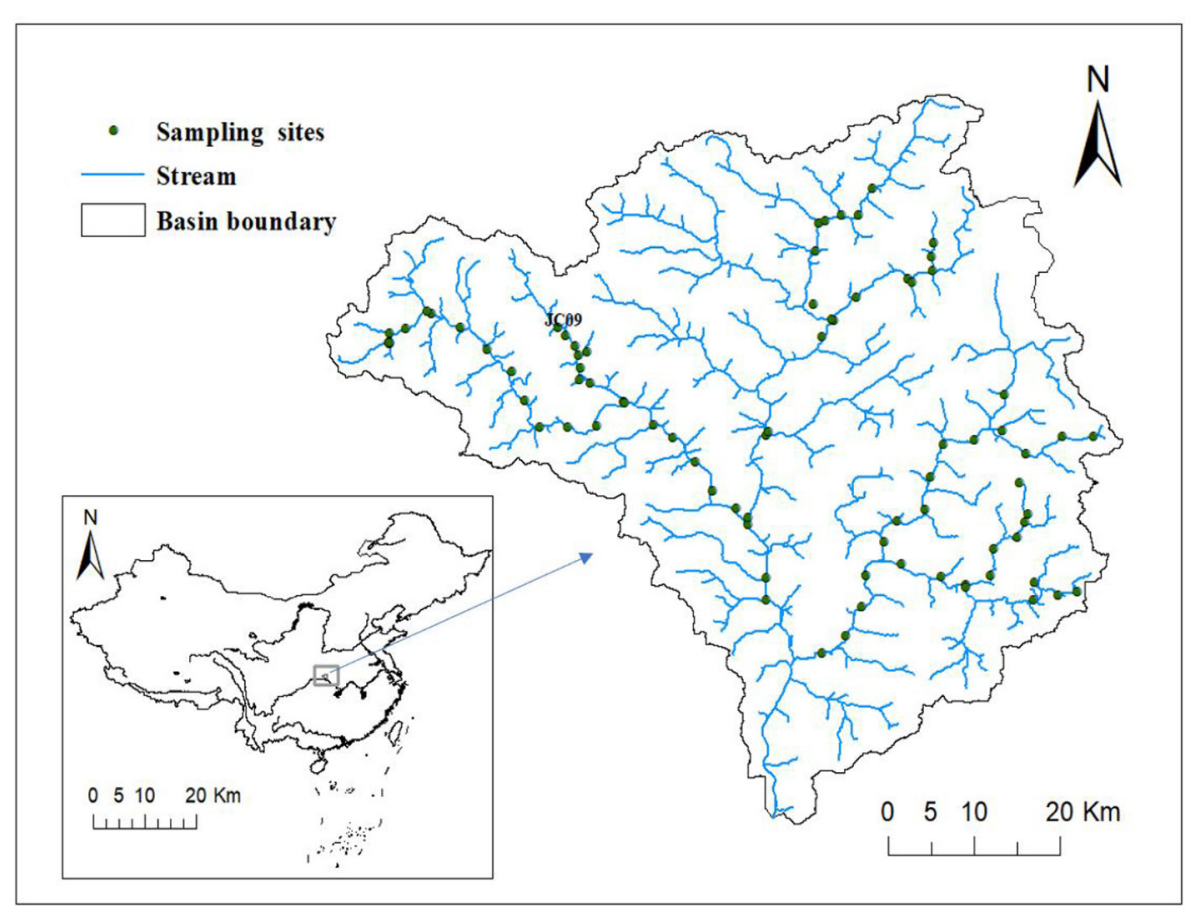

FIGURE 1 | Distribution of sampling sites in the Xiangxi River Basin.

dominant macroinvertebrate taxon, Baetis, for model testing based on its presence at most sampling sites across the watershed and a range of habitat affinities. In addition, the ecological water requirement was obtained by constructing an ecological niche model of this indicator taxon during different seasons. The objective of this study was to investigate the ecological flow based on niche modeling during dry and wet seasons and thus provide theoretical guidance for the management of hydropower plants. We hypothesized that seasonal changes in environmental flow occur when climatic variability influences habitat heterogeneity and life history of species.

\section{MATERIALS AND METHODS \\ Study Area}

This study was conducted in the Xiangxi River Basin of Central China (Figure 1). The Xiangxi River Basin has a northern subtropical monsoon climate, and some areas have temperate climate characteristics. The annual average precipitation is $900-$ $1,200 \mathrm{~mm}$. Rainfall in spring accounts for $28 \%$ of the annual rainfall; the summer climate is hot and humid, with rainfall accounting for $41 \%$ of the annual rainfall for the longest season. The autumn rainfall accounts for $26 \%$ of the annual rainfall; winter is cold and snowy for a long period, and the rainfall accounts for $5 \%$ of the annual rainfall (Wu, 1997; Hui et al., 2000; Li et al., 2013).

The Xiangxi River is located at $110^{\circ} 25^{\prime}-111^{\circ} 06^{\prime} \mathrm{E}$ longitude and $30^{\circ} 57^{\prime}-31^{\circ} 54^{\prime} \mathrm{N}$ latitude. It originates from the Shennongjia Forestry region, known as the "roof of central China." The forest coverage rate is $60.3 \%$, which is three times the national average forest coverage rate. The mountains are high with an elevation of more than $1,500 \mathrm{~m}$, among which Shennongding-the first peak in Central China-reaches 3,105 $\mathrm{m}$ and is the highest point in Central China and the main peak of Dabashan Mountain. Owing to its unique geographical advantages, the Xiangxi River Basin has rich forest and aquatic biological resources, becoming a transition region of animal and plant species in Central China (Zhu, 1999; Jiang, 2008).

The water system of the Xiangxi River Basin is characterized by a typical branch-shaped river network structure. The mainstream of the Xiangxi River, with a total length of $94 \mathrm{~km}$, is a main tributary of the Yangtze River. It has a basin area of $3,099 \mathrm{~km}^{2}$, a natural drop of $1,540 \mathrm{~m}$, and abundant water energy resources (Zhu, 1999). In 1978, the Gengjiahe hydropower station-the first hydropower plant in Xingshan County-started its hydroelectricity service in the Xiangxi River Basin. To meet the power demands, 84 hydropower plants were constructed along the Xiangxi River in Xingshan County by 2019.

\section{Data Acquisition}

In this study, the data set was collected from the ecosystem experiment stations of the Three Gorges Reservoir-Xiangxi River (hereafter referred to as the Xiangxi River station). We selected monthly data from July 2001 to June 2007. In addition, the samples were collected in June 2004, January 2007, and May 2007 across the entire basin. In total, 154 sampling sites (i.e., based on monthly and whole basin sampling) were selected, macroinvertebrates were collected, the physical and chemical 
factors of the water body were analyzed, and the river depth and flow velocity were measured.

Unlike fish, macroinvertebrates are largely ignored in environmental flow studies, which is surprising considering their high diversity (Barbour et al., 1999; Gore et al., 2001) and variable responses to environmental factors (Gore et al., 1998, 2001; Smith et al., 1999). These samples were used to construct the niche model for the mayfly genus Baetis (Insecta: Ephemeroptera), that is, the abundant macroinvertebrate taxon in this watershed (Jiang et al., 2009), during the dry and wet seasons. In the Xiangxi River Basin, the occurrence frequency of Baetis at various sites is $100 \%$, and the relative abundances range from 20 to $52 \%$ (Fu et al., 2008; Jiang et al., 2009). The mayfly taxon is an aquatic insect with flying adult stages.

Subsequently, based on the niche model, one sampling site (named JC09) was selected to assess the environmental flow and ecological water requirements. The sampling site is a natural river course without obvious human interference and is located in the upstream reaches of the Jiuchong River Power Station. The station is a typical diversion power station in the mainstream of the Xiangxi River. The data used for the environmental flow analysis were selected from the monthly cross-sectional flow measurement data of site JC09 from April 2017 to November 2019.

Three representative sections of each sampling site were selected to measure the width of the river using a tape measure. The flow velocity was measured at a depth of 0.6 times using a flow meter. For collecting macroinvertebrates, the D-frame net was used before June 2004, and then the Surber sampler (mesh size: $0.42 \mathrm{~nm}$; sampling area: $0.09 \mathrm{~m}^{2}$ ) was used for quantitative collection; $10 \%$ of formalin solution or $75 \%$ of alcohol solution for storage. Macroinvertebrates were identified based on the relevant literature (Morse et al., 1984).

Our stream reaches consist largely of riffles and runs. Based on the substrate measurement following the EPA standards (Barbour et al., 1999), the streambed of the Xiangxi River Basin is mainly composed of gravel $(2-16 \mathrm{~mm})$, pebble $(16-64 \mathrm{~mm})$, and cobble $(64-256 \mathrm{~mm})$. The riparian vegetation in the basin is mainly divided into broad-leaved forest, coniferous forest, mountain shrub and grass, bamboo forest, economic forest, and agricultural vegetation. The forest land area is $89,800 \mathrm{hm}^{2}$, and the forest coverage rate is $56.1 \%$.

\section{Niche Modeling}

In this study, we used a generalized additive model (GAM) for niche modeling. We constructed a niche model for the most dominant macroinvertebrate taxon (i.e., Baetis). In this study, data on water depth and velocity were highly available; hence, they were selected as habitat factors to construct the niche model of this indicator taxon. In the model, water depth and flow velocity were taken as explanatory factors, and the occurrence of the indicator taxon in habitats was taken as the response variable. In a habitat, if the indicator taxon was present, the occurrence value corresponding to the sampling habitat was 1. If the indicator taxon was absent from the sampling site, the occurrence value was 0 . We modeled the habitat suitability for a single habitat factor. Suitability can reflect the degree of preference of the indicator taxon and show the probability of its presence based on habitat factors (Bovee, 1982). The suitability value ranges between 0 and 1 , where 0 is the least suitable, indicating that species cannot survive under such conditions, and 1 is the most suitable (Bovee, 1982; Marchini et al., 2009).

The dynamic relationship between habitat suitability and environmental factors has the characteristics of complexity, nonlinearity, and uncertainty. Therefore, we used a GAM with high flexibility to estimate the functional relationship between the response and explanatory variables. GAM reflects the essential connection between the response variable and the explanatory variable rather than the parameter form, and it is suitable for explaining non-linear or non-monotonic data analysis (Ouyang and Feng, 2013). In this study, the "mgcv" package of the R language platform (Verbeke, 2007) was used to build the model.

\section{Ecological Water Requirement and Optimal Environmental Flow}

By using GAM, relationships were established between the weighted usable width (WUW) and flow discharge during the dry and wet seasons. The niche model was used to assess WUW based on the measured habitat factors. Based on the principle of the wetted perimeter method (Zhong et al., 2006), the point on the regression curve that intersects with a slope of $45^{\circ}$ is taken as the maximum turning point and is considered the minimum ecological water requirement. Its WUW will be significantly reduced and hence cannot meet the requirements of normal growth and reproduction of organisms.

The instream flow incremental methodology (IFIM) was applied to assess WUW. This methodology was first proposed by the U.S. Fisheries and Wildlife Conservation Agency to protect fish and macroinvertebrate habitats and meet the requirements of river ecological habitat conservation, stream regulation, and water resource development (Armour and Taylor, 2011). The width of the river determines the living area of aquatic organisms, such as fish and macroinvertebrates, and the flow rate is a restrictive factor that limits the choice of habitat for aquatic organisms (Stalnaker et al., 1995). In a river channel, a difference in the flow rate will alter the river width, thereby changing the suitable living area of aquatic organisms in the river ( $\mathrm{Li}$ and Xia, 2011). The IFIM applies to aquatic organisms as indicator species, based on a large number of field sampling observations of hydrological data, through niche modeling, using flow and biological indicators after estimating the effective survival area, e.g., WUW (Midcontinent Ecological Science Center, 2001; Yang and Zhang, 2003; Ahmadi-Nedushan et al., 2006) in this study, to compute the minimum ecological water requirement of rivers (Stalnaker et al., 1995; Midcontinent Ecological Science Center, 2001).

The channel section was divided into parts, and the environmental factors of each part were measured. By inputting these factors, the corresponding value of habitat suitability through the niche model of indicator organisms was used to 

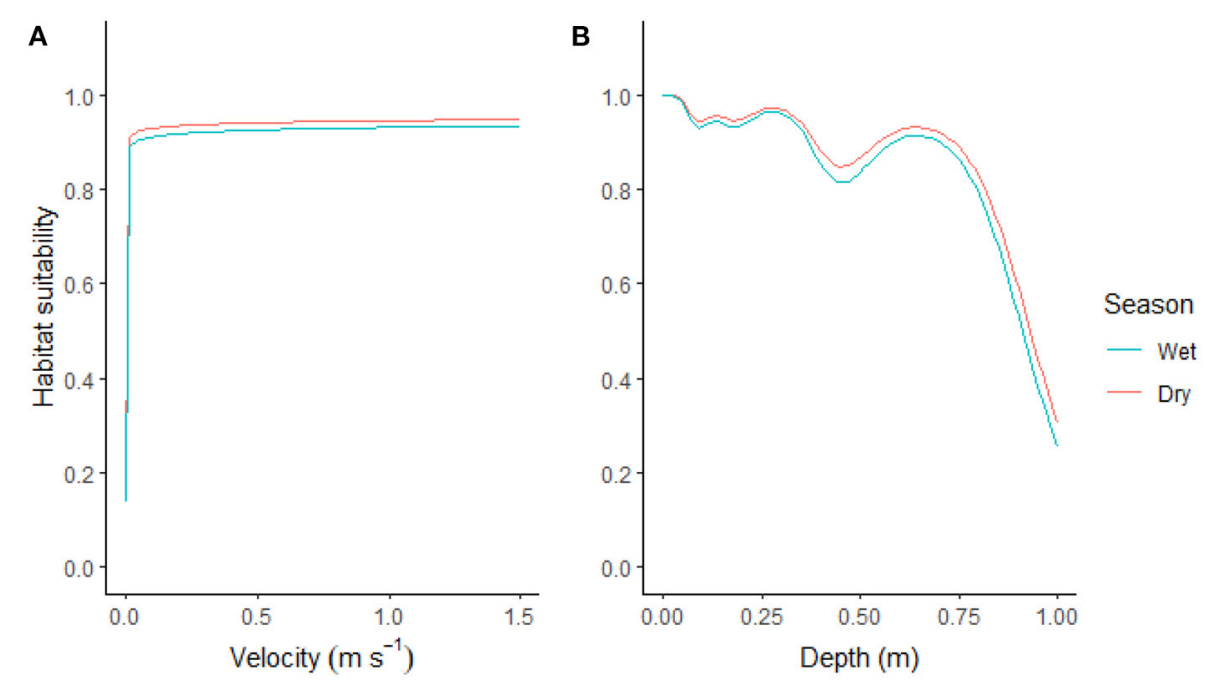

FIGURE 2 | (A) Velocity suitability for Baetis in Xiangxi River Basin and (B) depth suitability for Baetis in Xiangxi River Basin.

TABLE 1 | Generalized additive model results of the relationships between the habitat suitability of Baetis and environmental factors.

\begin{tabular}{llllll}
\hline $\begin{array}{l}\text { Environmental } \\
\text { factors }\end{array}$ & \multicolumn{3}{l}{ The habitat suitability of Baetis } & \\
\hline & $\begin{array}{l}\boldsymbol{p} \text { - } \\
\text { value }\end{array}$ & Chi.sq & edf & $\begin{array}{l}\text { Dev. } \\
\text { expl. }\end{array}$ & $\begin{array}{l}\text { Adjusted } \\
\boldsymbol{R}^{\mathbf{2}}\end{array}$ \\
\hline $\begin{array}{lllll}\text { Depth } \\
\text { Velocity }\end{array}$ & $0.001503^{*}$ & 24.878 & 6.809 & $17.4 \%$ & 0.119 \\
Season & 0.111609 & 1.417 & 0.534 & & \\
\hline
\end{tabular}

*Means significant difference $(P<0.05)$.

edf is the estimated degrees of freedom accounting for the smoothing function.

\#Deviance explained by the model with both factors.

calculate WUW in the section.

$$
\mathrm{WUW}=\sum F\left[f\left(D_{i}\right), f\left(V_{i}\right)\right] W_{i}
$$

where $D_{i}$ is the water depth of section $I, V_{i}$ is the water velocity of section $i, W_{i}$ is the water width of section $i, f\left(D_{i}\right)$ is the suitability of section $i$ based on water depth, $f\left(V_{i}\right)$ is the suitability of section $i$ based on flow velocity, $W_{i}$ is the water width of section $i, F[\bullet]$ is the suitability combination of section $i$, and WUW is the weighted usable width of section $i$.

\section{RESULTS}

\section{Habitat Suitability Model}

The ecological niche model of the indicator taxon (i.e., Baetis), with flow velocity and water depth as explanatory variables, is shown in Figure 2. Water depth had a significant effect on habitat suitability $(P<0.05)$, whereas velocity and season had no significant effect $(P>0.05)$ (Table 1$)$.

The measured velocity of the macroinvertebrates in the stream was in the range of $0.0-1.5 \mathrm{~m}^{3} \cdot \mathrm{s}^{-1}$ (Figure 2A). The habitat suitability in the flow velocity range was high, ranging from 0.9 to 1.0 , and the changing trends of the two periods (i.e., dry and wet seasons) were consistent. However, the suitability tended to decrease in the still water area with a flow rate of $0.0 \mathrm{~m}^{3} \cdot \mathrm{s}^{-1}$.

The depth of collection of macroinvertebrates from streams was between 0.1 and $1.0 \mathrm{~m}$ (Figure 2B). The habitat suitability during the dry and wet seasons changed with the same trend under the influence of water depth. The relationship between habitat suitability and water depth was non-linear. Overall, there was a negative correlation. The suitability value was greatly reduced in the stream section with a water depth of more than $0.7 \mathrm{~m}$ (i.e., the downstream section). The deep-water reach was not conducive to taxon survival. However, when the water depth exceeded $0.7 \mathrm{~m}$, the suitability decreased significantly. In addition, in the interval of $0.0-0.3 \mathrm{~m}$, the habitat suitability was relatively high without major fluctuations; the suitability value was stable at $0.9-1.0$. In the interval of $0.3-0.5 \mathrm{~m}$, the suitability decreased with an increase in water depth; the suitability value was between 0.8 and 1.0. At a water depth of $0.5-0.7 \mathrm{~m}$, the suitability value increased with an increase in water depth; the suitability value was between 0.8 and 1.0.

\section{Environmental Flow in the Xiangxi River Channel and WUW}

The environmental flow and seasonal factors had significant influences $(P<0.05)$ on the WUW of the Baetis species (Table 2 ). During the dry and wet seasons, the weighted available width increased with an increase in flow (Figure 3). Both WUW curves presented unimodal patterns but exhibited diverse changes during the dry and wet seasons. For example, when the discharge 
TABLE 2 | Generalized additive model results of the relationships between the habitat suitability of Baetis and the flow discharge and seasonal factors.

\begin{tabular}{llllll}
\hline Factors & \multicolumn{5}{c}{ Weighted usable width of Baetis } \\
\hline & $\begin{array}{l}\boldsymbol{p} \text { - } \\
\text { value }\end{array}$ & $\begin{array}{l}\boldsymbol{F} \text { - } \\
\text { value }\end{array}$ & edf & $\begin{array}{l}\text { Dev. } \\
\text { expl. }\end{array}$ & $\begin{array}{l}\text { Adjusted } \\
\boldsymbol{R}^{2}\end{array}$ \\
\hline $\begin{array}{l}\text { Flow } \\
\text { discharge } \\
\text { Season }\end{array}$ & $0.007196^{*}$ & 5.788 & 2.1976 & $67.5 \%$ & 0.615 \\
\hline
\end{tabular}

*Means significant difference $(P<0.05)$.

edf is the estimated degrees of freedom accounting for the smoothing function.

\#Deviance explained by the model with both factors.

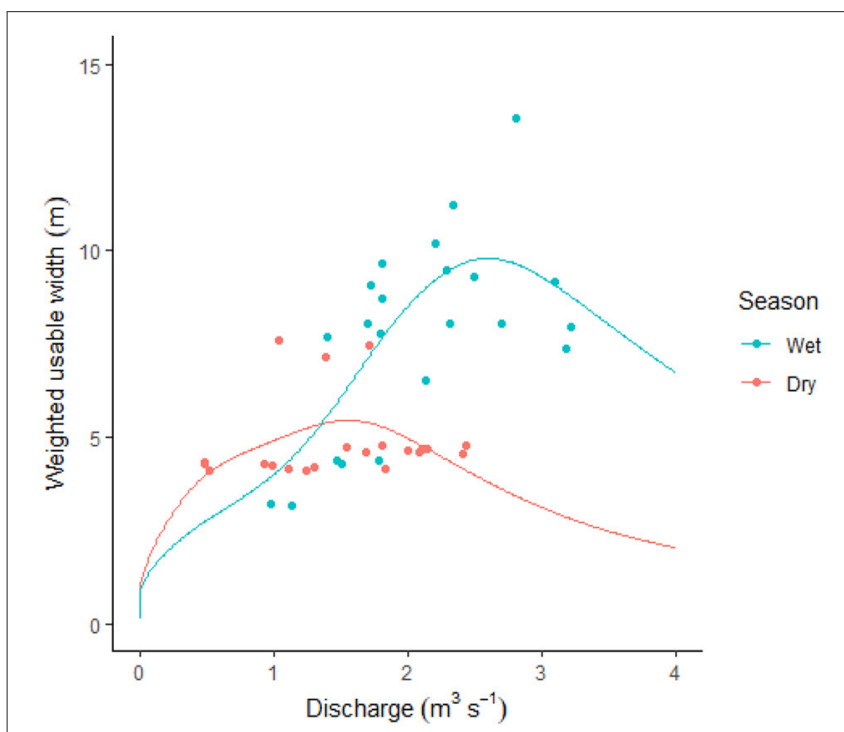

FIGURE 3 | Relationship between weighted usable width (WUW) and flow discharge for Baetis in the Xiangxi River Basin.

ranged from 0 to $1.3 \mathrm{~m}^{3} \cdot \mathrm{s}^{-1}$, the WUW during the dry season was higher than that during the wet season. When the discharge value was $1.3 \mathrm{~m}^{3} \cdot \mathrm{s}^{-1}$, the WUW during both dry and wet seasons was $5.2 \mathrm{~m}$. At a flow rate $>1.3 \mathrm{~m}^{3} \cdot \mathrm{s}^{-1}$, the WUW during the wet season was always higher than that during the dry season under the same discharge value. The highest weighted available width was observed. According to the wetted perimeter method, the maximum turning point of the curve in the ascending phase was determined as the minimum ecological water requirement; the values were 1.3 and $2.5 \mathrm{~m}^{3} \cdot \mathrm{s}^{-1}$ during the dry and wet seasons, respectively. The flow corresponding to the highest point of the curve was the optimal ecological flow, with a value of $1.6 \mathrm{~m}^{3} \cdot \mathrm{s}^{-1}$ during the dry season and $2.6 \mathrm{~m}^{3} \cdot \mathrm{s}^{-1}$ during the wet season.

\section{DISCUSSION}

In this study, the entire year was divided into dry and wet seasons to construct habitat models of indicator species. Our results support the hypothesis that the environmental flow differs during the wet and dry seasons. However, the seasonal difference was attributed to the hydrological influence on habitat heterogeneity rather than on the life history of this study taxon.

Numerous studies have shown that species with specific characteristics, such as fish, macroinvertebrates, and algae, have consistent responses to flow changes (Mcmanamay and Frimpong, 2015; Rolls and Sternberg, 2015). This alleviates the estimation of environmental flow by IFIM. Species with the same biological characteristics (such as functional traits, morphology, and physiological needs) were selected as indicator organisms for the construction of the niche model to further estimate the minimum ecological water requirement (Poff, 1997, 2017; Arthington et al., 2018), which is also the objective of our next research. The construction and accuracy of the ecological niche model is the basis for environmental flow assessment (Bovee, 1982; Fu et al., 2008; Li et al., 2008).

\section{Importance of the Habitat Suitability Model}

Using the robust and flexible statistical model (i.e., GAM), this study selected water depth and flow velocity as habitat factors to construct the niche model of the most dominant taxon in the Xiangxi River Basin (i.e., Baetis). The results showed that the habitat suitability was high at a minimum water depth of $0.1 \mathrm{~m}$. However, when the water depth reached $0.0 \mathrm{~m}$, this macroinvertebrate being aquatic and should not survive. In such a situation, there was still flowing water in the reach, but the depth was too shallow to be measured during sampling. When the water depth was more than $0.75 \mathrm{~m}$, the suitability value decreased significantly with the increase in depth and tended to 0 . The effect of flow velocity on Baetis was relatively low and insignificant; in the range of $0.0-1.5 \mathrm{~m}^{3} \cdot \mathrm{s}^{-1}$, the high suitability value fluctuated between 0.8 and 1.0. Flow velocity may not be a limiting factor in the Xiangxi River. The results of this study are considerably different from those of a previous study (Li et al., 2008), which was not based on niche modeling specific to this study area.

Several factors are responsible for the differences between the ecological effects of water depth and flow velocity. First, Baetis was the dominant species among the macroinvertebrates in this watershed. Its habitat range was relatively wide, and it could survive within the flow-velocity range of $0.0-1.5 \mathrm{~m}^{3} \cdot \mathrm{s}^{-1}$ (Jiang et al., 2008). Second, the maximum velocity of our streams was $1.5 \mathrm{~m}^{3} \cdot \mathrm{s}^{-1}$, and some areas with velocities higher than 1.5 $\mathrm{m}^{3} \cdot \mathrm{s}^{-1}$ have not yet been sampled due to safety and technical limitations. In future studies, more environmental factors that have a key impact on the community structure and biodiversity of stream macroinvertebrates, such as substrates (Stalnaker et al., 1995), need to be considered. In addition, data from different years can be added to construct a more accurate niche model to reveal the potential mechanisms of seasonal influences on the environmental flow requirements of macroinvertebrates.

In this study, the dry and wet seasons had different environmental flows. The ecological water requirements in the river course are not constant because it depends on the time fluctuation of river hydrology. The scientific research and management guidance of environmental flow should benefit based on the relationship between the natural flow regime and 
ecological response. Similarly, the ecological water requirements of different organisms are generally not equal. Habitat suitability and ecological water requirements of different species in the same basin, the same species in different basins, and species in different growth and reproduction periods vary (Poff, 1997, 2017; Frimpong and Angermeier, 2010). In this study, the habitat suitability model of Baetis presented a consistent fluctuation trend along the environmental gradients during the dry and wet seasons. Baetis forms a dominant macroinvertebrate assemblage, has a multivoltine life history, and its biodiversity is high in the watershed throughout the year (Poff et al., 2006; Jiang et al., 2009). However, the habitat suitability of species with other life histories, such as univoltine and semivoltine, can vary in different periods, and they will have their corresponding ecological water requirements. These aspects should be considered in the management of ecological water requirements, which need more precise and detailed niche models. In this study, although the Baetis species had similar suitability in different seasons, their overall environmental conditions and environmental flow requirements were remarkably different. This is the main rationale, rather than the life history, based on which we expected and studied the seasonal changes.

\section{Determination of the Threshold of Environmental Flow}

The IFIM does not yield the minimum ecological water requirement. The setting of its threshold should be synchronized with the comprehensive consideration of water resource management in ecological water, production water, and domestic water (Ying and Li, 2006). Based on the wetted perimeter method, this study estimated the minimum ecological water requirement (Ji et al., 2006). Although this method is feasible, it lacks a sufficient theoretical basis. The method to determine the threshold of environmental flow needs to be further improved based on the habitat conditions, characteristics of indicator organisms, and related theories of river ecology. In addition, this study showed the optimal environmental flow based on the non-linear relationship between the WUW and stream flow. This result presented a maximum threshold for ecological water requirement when there was functional maintenance of excessive flow of the river.

\section{Limitations and Future Development of the Environmental Flow Framework}

Habitat suitability models need to be constructed with dominant taxonomic groups as indicator species to calculate subsequent environmental flow, and it is difficult to apply uncommon species to these models. The dynamic relationships between indicator organisms and habitat factors can be characterized by complexity, non-linearity, and uncertainty due to the comprehensive effects of water depth, velocity, and physicochemical factors, among others. Therefore, we used the GAM to fit the indicator taxon for effective modeling. This model requires a large amount of baseline sampling survey data, which do not include shortterm and small-scale survey data, to avoid overfitting. Another limitation of this study is that the influence of the streambed substrate is not taken into account due to the lack of data. However, the substrate composition is similar in the selected study area. The method is feasible for this area, but it is recommended to consider the environmental effect in other areas with uneven substrate composition.

In this study, macroinvertebrates were selected as indicator species due to their higher diversity than that of traditional indicator species, such as fish in headstreams, which were more likely to show changes in the environmental parameters. However, in other watersheds, appropriate indicators should be selected according to the local conditions to construct habitat suitability models. Habitat suitability and ecological water requirements of species at different periods of growth and reproduction vary regardless of whether they are different species in the same watershed or the same species in different watersheds. Various elements in the ecosystem, such as water, species, nutrients, and energy resources, can be distributed actively or passively along the hydrological flow paths among microhabitats in the same basin. Therefore, the integration of metaecosystem approaches (i.e., multiple ecosystems interacting by species dispersal and material transportation) should be considered for the construction of prediction models in the future.

\section{CONCLUSION}

This study showed that the habitat suitability of Baetis in the Xiangxi River Basin exhibited the same pattern during the dry and wet seasons. However, the minimum ecological water requirements and optimal environmental discharge differed in the two seasons. There has been an increasing shortage of water resources and high ecological impacts of hydropower plants. Under constantly changing social, economic, and environmental conditions, environmental water strategies must surpass the traditional water supply (Bond et al., 2008; Rockstrom et al., 2014). For the determination of the environmental flow threshold and management implementation, it is necessary to maintain the functional value of the ecosystem and simultaneously meet the needs of human populations and social development (Cai et al., 2003). This management strategy can be achieved through a variety of scientific frameworks from a multidisciplinary perspective to jointly assess the environmental flow.

\section{DATA AVAILABILITY STATEMENT}

The original contributions presented in the study are included in the article Supplementary Materials, further inquiries can be directed to the corresponding author.

\section{AUTHOR CONTRIBUTIONS}

QL, M-CC, and QC: conceptualization and methodology. QL, M-CC, and LT: software. QL and M-CC: validation and writingreview and editing. QL and LT: investigation. QC: resources and 
funding acquisition. LT and QC: data curation. QL: writingoriginal draft preparation. All authors have read and agreed to the published version of the manuscript.

\section{FUNDING}

This study was funded by the National Key R\&D Program of China (No. 2017YFC0506406), the State Key Laboratory FEBL Research (No. 2019FBZ01), and the National Natural Science Foundation of China (No. 30330140).

\section{REFERENCES}

Aguiar, F. C., Martins, M. J., Silva, P. C., and Fernandes, M. R. (2016). Riverscapes downstream of hydropower dams: effects of altered flows and historical land-use change. Landsc. Urban Plan. 153, 83-98. doi: 10.1016/j.landurbplan.2016.04.009

Ahmadi-Nedushan, B., St-Hilaire, A., Berube, M., Robichaud, E., Thiemonge, N., and Bobee, B. (2006). A review of statistical methods for the evaluation of aquatic habitat suitability for instream flow assessment. River Res. Appl. 22, 503-523. doi: 10.1002/rra.918

Ali, R., Kuriqi, A., Abubaker, S., and Kisi, O. (2019). Long-term trends and seasonality detection of the observed flow in yangtze river using Mann-Kendall and Sen's Innovative Trend Method. Water 11, 1855-1872. doi: 10.3390/w11091855

Alsterberg, C., Roger, F., Sundback, K., Juhanson, J., Hulth, S., Hallin, S., et al. (2017). Habitat diversity and ecosystem multifunctionality-the importance of direct and indirect effects. Sci. Adv. 3:e1601475. doi: 10.1126/sciadv.1601475

Armour, C. L., and Taylor, J. G. (2011). Evaluation of the instream flow incremental methodology by U.S. Fish and Wildlife Service Field Users. Fisheries 16, 36-43. doi: 10.1577/1548-8446(1991)016<0036:EOTIFI > 2.0.CO;2

Arthington, A. H., Kennen, J. G., Stein, E. D., and Webb, J. A. (2018). Recent advances in environmental flows science and water management-Innovation in the Anthropocene. Freshw. Biol. 63, 1022-1034. doi: 10.1111/fwb.13108

Barbour, M. T., Faulkner, C., and Usepa, B. (1999). Rapid Bioassessment Protocols for Use in Streams and Wadeable Rivers Periphyton Benthic Macroinvertebrate and Fish, 2nd Edn. Washington, DC: United States Environmental Protection Agency Press.

Bond, N. R., Lake, P. S., and Arthington, A. H. (2008). The impacts of drought on freshwater ecosystems: an Australian perspective. Hydrobiologia 600, 3-16. doi: $10.1007 / \mathrm{s} 10750-008-9326-\mathrm{Z}$

Bovee, K. D. (1982). A Guide to Stream Habitat Analysis Using the Instream Flow Incremental Methodology. IFIP No. 12 (82/26). Availble online at: http://pubs. er.usgs.gov/publication/fwsobs82_26

Branco, C. W. C., Leal, J. J. F., Huszar, V. L. D., Farias, D. D., Saint'Pierre, T. D., Sousa, I. F., et al. (2019). New lake in a changing world: the construction and filling of a small hydropower reservoir in the tropics (Rio de Janeiro, Brazil). Environ. Sci. Pollution Res. 26, 36007-36022. doi: 10.1007/s11356-019-06665-y

Bunn, S. E., and Arthington, A. H. (2002). Basic principles and ecological consequences of altered flow regimes for aquatic biodiversity. Environ. Manage. 30, 492-507. doi: 10.1007/s00267-002-2737-0

Cai, Q. H., Tang, T., and Liu, J. K. (2003). Several research hotspots in river ecology. Chin. J. Appl. Ecol. 14, 1573-1577. http://ir.ihb.ac.cn/handle/152342/2262

Frimpong, E. A., and Angermeier, P. L. (2010). Trait-based approaches in the analysis of stream fish communities. Commun. Ecol. Stream Fishes Concepts Approaches Techn. 73, 109-136. doi: 10.47886/9781934874141.ch6

Fu, X. C., Wu, N. C., Zhou, S. H., Jiang, W. X., Li, F. Q., and Cai, Q. H. (2008). Impacts of a small hydropower plant on macroinvertebrate habitat and an initial estimate for ecological water requirement of Xiangxi River. Acta Ecol. Sin. 28, 1942-1948. doi: 10.3321/j.issn:1000-0933.2008.05.007

Gore, J. A., Crawford, D. J., and Addison, D. S. (1998). An analysis of artificial riffles and enhancement of benthic community diversity by physical habitat simulation (PHABSIM)

\section{ACKNOWLEDGMENTS}

We thank the reviewers for their many insightful comments and suggestions.

\section{SUPPLEMENTARY MATERIAL}

The Supplementary Material for this article can be found online at: https://www.frontiersin.org/articles/10.3389/fevo. 2021.734716/full\#supplementary-material

and direct observation. Regul. Rivers Res. Manage. 14, 69-77. doi: 10.1002/(SICI)1099-1646(199801/02)14:1<69::AID-RRR477>3.0.CO;2-D

Gore, J. A., Layzer, J. B., and Mead, J. (2001). Macroinvertebrate instream flow studies after 20 years: a role in stream management and restoration. Regul. Rivers Res. Manage. 17, 527-542. doi: 10.1002/rrr.650

Halleraker, J. H., Sundt, H., Alfredsen, K. T., and Dangelmaier, G. (2007). Application of multiscale environmental flow methodologies as tools for optimized management of a Norwegian regulated national salmon watercourse. River Res. Appl. 23, 493-510. doi: 10.1002/rra.1000

Hong, S. Y., Wang, H. R., Zhu, Z. F., and Han, L. J. (2018). Research of ecologic flow based on habitat index method. Resourc. Environ. Yangtze Basin 27, 168-175. doi: 10.11870/cjlyzyyhj201801019

Hough, I. M., Warren, P. H., and Shucksmith, J. D. (2019). Designing an environmental flow framework for impounded river systems through modelling of invertebrate habitat quality. Ecol. Indic. 106. doi: 10.1016/j.ecolind.2019.105445

Huang, J., Chen, W., Wen, Z., Zhang, G., Li, Z., Zuo, Z., et al. (2019). Review of Chinese atmospheric science research over the past 70 years: climate and climate change. Sci. Sin. 49, 1607-1640. doi: 10.1007/s11430-019-9483-5

Hui, Y., Zhang, X. H., and Chen, Z. J. (2000). Present situation and strategy about the natural environment of the Xiangxi river basin. Resourc. Environ. Yangtze Basin 9, 28-34. doi: 10.1007/s11769-000-0008-7

Ji, L. N., Liu, S. X., Hong-Xing, L. U., and Men, B. H. (2006). Theoretical study of minimum instream flow requirement using the wetted perimeter method. J. Northwest Sci. Tech Univ. Agricult. Forestry 34, 124-130. doi: 10.1016/S1872-1508(06)60066-1

Jiang, W. X. (2008). Impact of human activities on macroinvertebrate communities in Xiangxi River, Three-Gorge Region (the degree of Master of Science). Institute of hydrobiology, Chinese academy of Sciences, Wuhan, China.

Jiang, W. X., Cai, Q. H., Tang, T., Wu, N. C., and Liu, R. Q. (2008). Spatial distribution of macroinvertebrates in Xiangxi River. Chin. J. Appl. Ecol. 19, 2443-2448. http://ir.ihb.ac.cn/handle/152342/504

Jiang, W. X., Fu, X. C., Tang, T., and Cai, Q. H. (2009). Community structure and niche of macroinvertebrates in the Xiangxi River in Hubei, China. Chin. J. Appl. Environ. Biol. 15, 51-55. doi: 10.3724/sp.j.1145.2009.00337

Kuriqi, A., Pinheiro, A. N., Sordo-Ward, A., Bejarano, M. D., and Garrote, L. (2021). Ecological impacts of run-of-river hydropower plants-current status and future prospects on the brink of energy transition. Renew. Sustain. Energy Rev. 142. doi: 10.1016/j.rser.2021.110833

Kuriqi, A., Pinheiro, A. N., Sordo-Ward, A., and Garrote, L. (2020). Water-energyecosystem nexus: balancing competing interests at a run-of-river hydropower plant coupling a hydrologic-ecohydraulic approach. Energy Convers. Manage. 223. doi: 10.1016/j.enconman.2020.113267

Li, F. Q., Cai, Q. H., Fu, X. C., and Liu, J. K. (2008). Construction of habitat suitability models (HSMs) for benthic macroinvertebrate and their applications to instream environmental flows: a case study in Xiangxi River of Three Gorges Reservior region, China. Science Direct 18, 1417-1424. doi: 10.1016/j.pnsc.2008.07.011

Li, F. Q., Cai, Q. H., Jiang, W. X., and Qu, X. D. (2012a). Macroinvertebrate relationships with water temperature and water flow in subtropical monsoon streams of Central China: implications for climate change. Fundamental Appl. Limnol. 180, 221-231. doi: 10.1127/1863-9135/2012/0220 
Li, F. Q., Cai, Q. H., Jiang, W. X., and Qu, X. D. (2012b). The response of benthic macroinvertebrate communities to climate change: evidence from subtropical mountain streams in Central China. Int. Rev. Hydrobiol. 97, 200-214. doi: 10.1002/iroh.201111489

Li, J., and Xia, Z. Q. (2011). Study on instream ecological flow of the middle Yangtze River based on physical habitat simulation. Shuili Xuebao J. Hydraulic Eng. 42, 678-684. doi: 10.1080/01688638808402819

Li, X. G., Wang, Z. X., Zhu, J. L., Wan, J., Guo, T., Liu, Q., et al. (2013). Preliminary study on hydrologic characteristics of main rivers in Shennongjia forest region. J. Hubei Univ. 35, 6-10.

Marchini, A., Facchinetti, T., and Mistri, M. (2009). F-IND: a framework to design fuzzy indices of environmental conditions. Ecol. Indic. 9, 485-496. doi: 10.1016/j.ecolind.2008.07.004

Mcmanamay, R. A., and Frimpong, E. A. (2015). Hydrologic filtering of fish life history strategies across the United States: implications for stream flow alteration. Ecol. Appl. 25, 243-263. doi: 10.1890/14-0247.1

Midcontinent Ecological Science Center (2001). PHABSIM for Windows Manual and Exercise. Washington, DC: U.S. Geological Survey.

Mittal, N., Bhave, A. G., Mishra, A., and Singh, R. (2015). Impact of human intervention and climate change on natural flow regime. Water Resourc. Manage. 30, 685-699. doi: 10.1007/s11269-015-1185-6

Morse, J. C., Yang, L., and Tian, L. (1984). Aquatic Insects of China Useful for Monitoring Water Quality. Nanjing: Hohai University Press.

Ouyang, F., and Feng, G. E. (2013). Nonlinear analysis of insect population dynamics based on generalized additive models and statistical computing using R. Chin. J. Appl. Entomol. 50, 1170-1177. doi: 10.7679/j.issn.2095-1353.2013.161

Pang, M. Y., Zhang, L. X., Ulgiati, S., and Wang, C. B. (2015). Ecological impacts of small hydropower in China: insights from an emergy analysis of a case plant. Energy Policy 76, 112-122. doi: 10.1016/j.enpol.2014.10.009

Papadaki, C., and Dimitriou, E. (2021). River flow alterations caused by intense anthropogenic uses and future climate variability implications in the balkans. Hydrology 8:7. doi: 10.3390/hydrology8010007

Poff, N. L. (2017). Beyond the natural flow regime? Broadening the hydroecological foundation to meet environmental flows challenges in a nonstationary world. Freshw. Biol. 16, 391-409.

Poff, N. L. (1997). Landscape filters and species traits: towards mechanistic understanding and prediction in stream ecology. J. North Am. Benthol. Soc. 16, 391-409. doi: $10.2307 / 1468026$

Poff, N. L. (2018). Beyond the natural flow regime? Broadening the hydroecological foundation to meet environmental flows challenges in a nonstationary world. Freshw. Biol. 63, 1011-1021. doi: 10.1111/fwb.13038

Poff, N. L., Olden, J. D., Vieira, N. K. M., Finn, D. S., Simmons, M. P., and Kondratieff, B. C. (2006). Functional trait niches of North American lotic insects: traits-based ecological applications in light of phylogenetic relationships. J. North Am. Benthol. Soc. 25, 730-755. doi: 10.1899/0887-3593(2006)0250730:FTNONA2.0.CO;2

Pragana, I., Boavida, I., Cortes, R., and Pinheiro, A. (2017). Hydropower plant operation scenarios to improve brown trout habitat. River Res. Appl. 33, 364-376. doi: 10.1002/rra.3102

Premalatha, M., Abbasi, T., and Abbasi, S. A. (2014). A critical view on the eco-friendliness of small hydroelectric installations. Sci. Total Environ. 481, 638-643. doi: 10.1016/j.scitotenv.2013.11.047

Prota Salomão, V., Tonin, A. M., de Souza Rezende, R., Marques Leite, G. F., Cunha Carvalho Alvim, E. A., Brandão Quintão, J. M., et al. (2019). Small dam impairs invertebrate and microbial assemblages as well as leaf breakdown: a study case from a tropical savanna stream. Limnologica 77, 125685-125685. doi: 10.1016/j.limno.2019.125685

Rockstrom, J., Falkenmark, M., Allan, T., Folke, C., Gordon, L., Jagerskog, A., et al. (2014). The unfolding water drama in the Anthropocene: towards a resiliencebased perspective on water for global sustainability. Ecohydrology 7, 1249-1261. doi: 10.1002/eco.1562

Rolls, R. J., and Sternberg, D. (2015). Can species traits predict the susceptibility of riverine fish to water resource development? An Australian Case Study. Environ. Manage. 55, 1315-1326. doi: 10.1007/s00267-015-0462-8
Ruocco, A. M. C., Portinho, J. L., and Nogueira, M. G. (2019). Potential impact of small hydroelectric power plants on river biota: a case study on macroinvertebrates associated to basaltic knickzones. Brazil. J. Biol. 79, 722-734. doi: 10.1590/1519-6984.1 91148

Smith, M. J., Kay, W. R., Edward, D., Papas, P. J., and Halse, S. A. (1999). AusRivAS: using macroinvertebrates to assess ecological condition of rivers in Western Australia. Freshw. Biol. 41, 269-282. doi: 10.1046/j.1365-2427.1999.0 0430.x

Stalnaker, C., Lamb, B., Henriksen, J., Bovee, K., and Bartholow, J. (1995). The Instream Flow Incremental Methodology: A Primer for IFIM, Vol. 29. Fort Collins, CO: United States National Biological Service.

Tharme, R. E. (2003). A global perspective on environmental flow assessment: emerging trends in the development and application of environmental flow methodologies for rivers. River Res. Appl. 19, 397-441. doi: 10.1002/ rra.736

Verbeke, T. (2007). Generalized additive models: an introduction with R. J. R. Stat. Soc. Ser. Stat. Soc. 170, 262-262. doi: 10.1111/j.1467-985X.2006.004 55_15.x

Wang, M. (2019). Research on the supervision of small hydropower ecological flow in china. J. North China Electric Power Univ. 2019, 18-25. doi: 10.14092/j.cnki.cn11-3956/c.2019.01.002

Wang, X. Z., Cai, Q. H., Jiang, W. X., and Qu, X. D. (2013). Assessing impacts of a dam construction on benthic macroinvertebrate communities in a mountain stream. Fresenius Environ. Bull. 22, 103-110. doi: $10.1080 / 10643389.2012 .671750$

Wellnitz, T. (2014). Can current velocity mediate trophic cascades in a mountain stream? Freshw. Biol. 59, 2245-2255. doi: 10.1111/fwb.12427

Wu, Z. J. (1997). Xingshan County Annals. Yichang: China Three Gorges press.

Yang, Z. F., and Zhang, Y. (2003). Comparison of methods for ecological and environmental flow in river channels. J. Hydrodyn. 8, 294-301.

Yi, Y. J., and Zhang, S. H. (2019). Review of aquatic species habitat simulation method and modelling. Sci. China Technol. Sci. 49, 5-19. doi: 10.1360/N092018-00217

Ying, X. M., and Li, L. (2006). Review on instream flow incremental methodology (IFIM) and applications. Acta Ecol. Sin. 26, 1567-1573.

Zhang, Y. Y. (2019). Comparative analysis of hydrologic synthesis method based on environmental flow rate. Heilongjiang Hydraulic Sci. Technol. 8, 82-84.

Zhao, W. H., Peng, Z. H., Wang, Z. H., and Li, Q. Y. (2015). Studies on macrozoobenthic community structure and the impacts of small hydropower plants in Jinggu river, Yunnan province. Resourc. Environ. Yangtze Basin 24, 310-318. doi: 10.11870/cjlyzyyhj201502018

Zhong, H. P., Liu, H., and Geng, L. H. (2006). Review of assessment methods for instream ecological flow requirements. Adv. Water Sci. 17, 430--434.

Zhu, Z. Q. (1999). Scientific Investigation of Shennongjia Nature Reserve, 2019. Beijing: China Forestry Publishing.

Conflict of Interest: The authors declare that the research was conducted in the absence of any commercial or financial relationships that could be construed as a potential conflict of interest.

Publisher's Note: All claims expressed in this article are solely those of the authors and do not necessarily represent those of their affiliated organizations, or those of the publisher, the editors and the reviewers. Any product that may be evaluated in this article, or claim that may be made by its manufacturer, is not guaranteed or endorsed by the publisher.

Copyright $\odot 2021 \mathrm{Luo}$, Chiu, Tan and Cai. This is an open-access article distributed under the terms of the Creative Commons Attribution License (CC BY). The use, distribution or reproduction in other forums is permitted, provided the original author(s) and the copyright owner(s) are credited and that the original publication in this journal is cited, in accordance with accepted academic practice. No use, distribution or reproduction is permitted which does not comply with these terms. 


\section{NOMENCLATURE}

$\begin{array}{ll}\begin{array}{ll}\text { A. Abbreviations and acronyms in alphabetic order } \\ \text { IFIM }\end{array} & \text { Instream Flow Incremental Methodology } \\ \text { GAM } & \text { Generalized Additive Model } \\ \text { WUW } & \text { Weighted Usable Width [m] } \\ \text { C. Parameters } & \text { the water depth of section } i \\ D_{i} & \text { the water velocity of section } i \\ V_{i} & \text { the water width of section } i \\ W_{i} & \\ \text { E. Variables } & \text { the suitability of section } i \text { based on water depth } \\ f\left(\mathrm{D}_{i}\right) & \text { the suitability of section } i \text { based on flow velocity } \\ f\left(\mathrm{~V}_{i}\right) & \text { the suitability combination of section } i \\ \mathrm{~F}[\bullet] & \end{array}$

